\title{
MICROEMPREENDEDOR INDIVIDUAL E AS VANTAGENS DA FORMALIZAÇÃO
}

\section{INDIVIDUAL MICRO-ENTREPRENEUR AND AS ADVANTAGES OF FORMALIZATION}

Recebido em 09.01.2019 Aprovado em 10.12.2019

Avaliado pelo sistema double blind revien

Larissa Souza Nascimento

DOI: https://doi.org/10.32888/cge.v7i2.27646

larissa.snascimento2015@gmail.com

Universidade CEUMA-São Luís/Maranhão, Brasil

Paulo Roberto Campelo Fonseca e Fonseca

fonseca.e.fonseca@hotmail.com

Universidade CEUMA-São Luís/Maranhão, Brasil

Mauro Leray Costa

mauro.leray@leray.com.br

Universidade CEUMA-São Luís/Maranhão, Brasil

Jaylson Franklin Mendonça Nunes

jaylson@geor.com.br

Universidade CEUMA- São Luís/Maranhão, Brasil

Thiago Cardoso Ferreira

thiagocardosof.adm@gmail.com

Universidade CEUMA- São Luís/Maranhão, Brasil

\section{Resumo}

O artigo exposto aborda a respeito do programa microempreendedor Individual e suas vantagens. Como objetivo de pesquisa, buscou-se analisar a percepção dos empreendedores acerca dos benefícios do programa governamental do microempreendedor Individual. Sendo assim, apresenta como problemática de pesquisa o seguinte questionamento: como os empreendedores percebem as vantagens do programa governamental do Microempreendedor Individual? A metodologia aplicada na pesquisa caracteriza-se como descritiva, tendo uma abordagem quantitativa. Para a coleta de dados, utilizou-se aplicação de formulário com 136 empreendedores, que foi aplicado in loco em um centro comercial, feira do João Paulo na cidade de São Luís do Maranhão. O formulário aplicado utilizou afirmações com opções baseadas na escala likert. Por meio dos resultados obtidos, constatou-se que apesar da maioria dos empreendedores não possuírem conhecimento sobre o programa e seus benefícios, consideram com base nas assertivas, que esses possuem relevância para o seu negócio.

Palavras-chave: Programa. Microempreendedor Individual. Vantagens.

\section{Abstract}

The presented article approaches about the Individual Microentrepreneur program and its advantages. As a general objective of research, it was sought to analyze the perception of entrepreneurs about the benefits of the governmental program of the Individual microentrepreneur. Thus, the following question is presented as a research problem: how do entrepreneurs perceive the advantages of the governmental program of the Individual microentrepreneur? The methodology applied in the research is characterized as descriptive, with a quantitative approach. For data collection, it was used a form application with 136 entrepreneurs, which was applied in loco at Feira do João Paulo in the city of São Luís do Maranhão. The applied form used assertions with options based on the Likert scale. Through the results obtained, it was found that although most entrepreneurs do not possess knowledge about the program and its benefits, they consider based on the assertives that they have relevance to their business.

Keywords: Program. Individual Micro-entrepeneur. Advantages. 


\section{Introdução}

Diante da crise e recessão econômica, enfrentadas pelo Brasil no início do segundo decênio do século XXI, observou-se, de maneira crescente, o número de indivíduos que exerce uma atividade por conta própria em pequenos negócios e na prestação de serviços, os chamados empreendedores informais. Uma grande parte desses empreendedores são impulsionados pela necessidade, na busca por uma alternativa de sobrevivência, observam uma forma de inserir-se no mercado de trabalho na perspectiva de obter uma renda que venha garantir o seu sustento. Para muitos, trabalhar na informalidade era visto com uma vantagem, pois não seria necessário lidar com a burocracia requerida pela formalização. Empiricamente, avaliam a formalização como um meio pelo qual o governo recolheria ainda mais impostos, ou seja, dificultaria ainda mais o crescimento do negócio.

Porém, atuar na informalidade implica dizer que estes empreendedores estarão desprovidos da proteção que o Governo oferece para os trabalhadores formalizados. Com o objetivo de diminuir a taxa de empresas informais no país, foi criada a Lei Complementar nº128/2008. Essa lei foi uma iniciativa do Estado com o intuito de criar condições especiais para a formalização de milhares de negócios informais existentes no Brasil, possibilitou-se aos empreendedores exercerem suas atividades legalmente, aumentar sua renda e inclusão social. A motivação empreendedora pretende, além da legalização do empreendimento, acelerar o crescimento financeiro da sociedade, e, através da formalização, garantir ao empreendedor vantagens que venham alavancar ainda mais a sua atividade.

Sendo assim, foi instituída a figura jurídica do Microempreendedor Individual- MEI, originado para facilitar ao indivíduo, outrora informal, a possibilidade da legalização e inscrição do seu negócio. $\mathrm{O}$ programa do Microempreendedor Individual tem como objetivo alcançar as atividades dos pequenos empresários, que, através da sua formalização, gozarão de uma série de vantagens que o próprio comporta. Os empreendedores, que buscam a formalização, passarão por um método desburocratizado, decrescimento da carga tributária, dispensa de tributos federais, capacidade para abrir uma conta bancária jurídica e outros serviços oferecidos para garantir um melhor desempenho de sua atividade empreendedora.

A relevância do tema para a sociedade implica destacar a importância para a economia brasileira, pois o MEI é um dos elementos que movimentam a economia do país. Observou-se, também, que por ser uma temática pouco explorada, a pesquisa, quando destinada para este campo, ou seja, da investigação, contribuirá para obter um maior conhecimento sobre o assunto e servir de base para novos estudos. Nesse contexto, para o pesquisador, o tema abordado permitirá identificar a importância do programa e a sua relevância no âmbito social.

Em semelhança com o que foi exposto, evidencia-se o seguinte problema: como os empreendedores percebem as vantagens do programa governamental do Microempreendedor Individual? Tal questionamento há de demandar tanto uma verificação bibliográfica quanto a utilização de instrumentos de análise ou recolhimento de informações aptas a viabilizarem que o assunto analisado alcance o objetivo geral da pesquisa: analisar a percepção dos empreendedores acerca dos benefícios do programa governamental do Microempreendedor Individual. Para um maior embasamento teórico, os principais autores utilizados na pesquisa, são: Baggio e Baggio (2015); Costa, Barros e Carvalho (2011); Oliveira (2014), além de outros que contribuíram para que se alcance uma resposta satisfatória no final deste artigo.

\section{Fundamentação Teórica}


Para que o presente artigo atinja seus propósitos, é necessário que se faça uma contextualização acerca das teorias e artigos existentes, cujo propósito foi oferecer consistência técnica-científica a este trabalho. Nesse sentido, é requerida uma abordagem aos seguintes temas: Empreendedorismo por necessidade ou oportunidade; Desenvolvimento socioeconômico; Programa MEI que se compreende ser o caminho para a verificação do problema produzido neste artigo.

\section{Empreendedorismo por Necessidade ou Oportunidade.}

Existem dois tipos de empreendedorismo, a saber, o empreendedorismo por necessidade, em que a motivação para a criação do negócio é quando não existe nenhuma outra alternativa de fonte de renda, e o empreendedorismo por oportunidade, em que a razão para abertura do negócio é pela visualização de uma oportunidade rentável (BAGGIO; BAGGIO, 2015). Rocha (2014) explica que o empreendedorismo por necessidade está subordinado ao decaimento da atividade econômica, ou seja, a diminuição da oferta de emprego, consequentemente gera desemprego. Esta queda tem conduzido pessoas a iniciarem a abertura de pequenos negócios, com o intuito de garantir sua subsistência.

Para Havreluck, Leal e Bertolazo (2016), a pessoa que é incentivada pela oportunidade caracteriza-se por empreendedor voluntário, ou seja, é o empreendedor que consegue enxergar novas oportunidades de negócios, além de visar à criação de uma atividade que terá utilidade e que conduzirá a manifestação de novas tendências de mercado. $\mathrm{O}$ empreendedor por oportunidade busca, através do descobrimento, uma chance de melhorar as condições de vida ao identificar uma oportunidade de empreender. Os autores explicam que este tipo de empreendedor possui uma visão voltada para o crescimento e geração de lucro para o seu empreendimento, busca-se elevar a sua participação tanto no seu ambiente local, quanto contribuir no cenário nacional (HAVRELUCK; LEAL; BERTOLAZO, 2016).

Ao avaliar quais são os motivos que levam uma pessoa a ingressar na atividade empreendedora, podem-se destacar essas duas variáveis como as principais motivações para um indivíduo envolver-se com o empreendedorismo: empreender por necessidade e empreender por oportunidade. $\mathrm{O}$ empreendedor por necessidade descreve um fragmento da população que busca o empreendedorismo por não encontrar alternativa de trabalho e por visar uma melhora econômica. Já o empreendedor por oportunidade corresponde àquela parcela da população que demanda a ocupação empreendedora ao conjecturar uma oportunidade de desenvolver um negócio, dentre outras opções em que poderia seguir (VALE; CORRÊA; REIS, 2014).

Uma pesquisa feita pelo Global Entrepreneurship Monitor - GEM no ano de 2016 reforça que o empreendedorismo por necessidade é aquele cuja principal motivação é a busca por uma chance de sobrevivência e obtenção de uma renda, abriu espaço para o empreendedorismo por oportunidade. Observa-se que isso é bastante positivo, pois alguns novos empreendedores brasileiros optam pela abertura de um negócio não por falta de emprego ou necessidade, mas porque conseguem enxergar uma oportunidade rentável e consequentemente uma melhora substancial na sua qualidade de vida (GEM, 2016).

Com isso, a abertura de novos negócios tem sido considerada de grande importância para muitos estudos e um dos principais pontos abordados é qual o impacto no desenvolvimento socioeconômico gerado nas nações, com os diferentes resultados do empreendedorismo. Portanto, destaca-se que o empreendedorismo por oportunidade possui um efeito positivo e, assim, considera-se que empreender por oportunidade gera um melhor resultado no desenvolvimento econômico de um país, pois apresenta uma relação alta com a capacidade de inovação por parte da atividade empreendedora (ROCHA, 2014). 


\section{Desenvolvimento Socioeconômico}

Até o Século XX, o desenvolvimento socioeconômico de um país era avaliado apenas por um aumento constante no nível de renda, sem se preocupar como esse aumento era distribuído (OLIVEIRA, 2002). Porém, essa ideia sobre o desenvolvimento vem sendo alvo de inúmeras discussões, pois além dos fatores econômicos impulsionarem o desenvolvimento socioeconômico, se faz necessária a inclusão de outras variáveis. Além da concepção relacionada meramente aos rendimentos financeiros, para que seja gerado o desenvolvimento socioeconômico, devem-se incluir os benefícios ligados ao crescimento do conforto e bem-estar da população (BERNADOR; VIEIRA; ARAUJO, 2013).

Assim sendo, seja qual for o ponto de vista, é imprescindível que ao abordar sobre o desenvolvimento socioeconômico, não seja feita a relação entre o crescimento econômico associado com a melhora na qualidade de vida das pessoas. Considera-se fundamental acrescentar as modificações que compõem o produto, como também os bens necessários em cada setor da economia, com o objetivo de potencializar os elementos que promovem o bem-estar econômico e social. Ao pensar em desenvolvimento de uma nação, busca-se elevar o nível de distribuição de renda, oferecer uma educação de qualidade, possuir um sistema de saúde eficiente, assim como destacar a importância do meio ambiente (OLIVEIRA, 2002).

Logo, pode-se dizer que o desenvolvimento socioeconômico é definido com relação ao conjunto de duas variáveis: aumento da sua capacidade produtiva e condição de vida mais adequada para a população. Portanto, busca-se proporcionar aos cidadãos uma igualdade de fatores, visa a diminuição tanto da pobreza como da desigualdade social. Deve-se elencar a maximização dos elementos que compõem uma gama de benefícios à sociedade (MOREIRA, 2009).

A partir disso, vale destacar a importância do empreendedorismo no desenvolvimento socioeconômico. A concepção de novos pontos de comercialização de bens ou serviços instiga o desenvolvimento, à vista que a capacidade de empreender está associada na maioria das vezes à inovação e às grandes mudanças. Nesse contexto, possuem uma capacidade de provocar o crescimento econômico, assim como possui no âmbito comunitário a chance de situar os seus esforços por meio da atividade empreendedora para o seu respectivo crescimento. Considera-se que ao criar um negócio, é possível mudar a realidade econômica e social, pois ao conduzir a criação de atividades empreendedoras que sejam inovadoras, essas agregam valores econômicos e sociais (ROCHA, 2014)

Porém, Havreluck, Leal e Bertolazo (2016) citam que o empreendedorismo por necessidade, idealizado em consequência da falta de opção, a qual busca por uma melhora financeira não gera o desenvolvimento socioeconômico, pois esse tipo de empreendimento foi criado a partir de um momento difícil como a falta de emprego, observa-se que não possui um planejamento desta atividade. Por isso, a atividade empreendedora por necessidade não propicia o desenvolvimento socioeconômico tanto quanto a atividade empreendedora por oportunidade (COSTA; BARROS; CARVALHO, 2011).

Uma investigação realizada por Barros e Pereira (2008) analisou a taxa de desemprego e a taxa de empreendedorismo de 853 municípios mineiros, consta-se que a quantidade de desemprego varia de maneira inversa com o crescimento econômico e com o índice de empreendedorismo, assim sendo, constatando que há uma relação contrária entre a atividade empreendedora por necessidade e o crescimento econômico. Isso se deve à falta de políticas públicas que venham a fomentar o empreendedorismo motivado por oportunidade e que reduzam a carga tributária, a fim de gerar uma economia forte em geração de emprego e renda (BARROS; PEREIRA, 2008).

Assim, como os dados do GEM (2015) afirmam que em 2014, 30\% da população brasileira sonha em ter o seu próprio negócio, ou seja, destaca-se o empreendedorismo entre o terceiro maior desejo das pessoas, perde-se somente para o sonho de possuir sua casa própria e fazer uma viagem pelo país, 
com um percentual de $41 \%$ e $32 \%$ respectivamente. Dada a importância do empreendedorismo por oportunidade, fica evidente a carência por parte do estado de criar políticas que venham impulsionar o empreendedorismo, pois além do fornecimento de direitos básicos, como saúde e educação de qualidade, considera-se necessária a criação de políticas públicas capazes de alavancar o desenvolvimento socioeconômico (LASCALA; SAETA; ANDRADE, 2016)

Consequentemente é importante considerar que o empreendedorismo por oportunidade tem sido de grande relevância no cenário econômico e social, logo que ao ser motivado pela oportunidade, é percebido que existe um planejamento para abertura do negócio, bem como possui estritamente uma relação com agentes inovadores. Logo, o empreendedorismo por oportunidade contribui positivamente para o desenvolvimento socioeconômico de uma nação, de maneira a contribuir tanto de forma econômica, como social através da melhora na qualidade de vida das pessoas (ROCHA, 2014).

\section{Programa MEI}

A informalidade tem se destacado a partir do final do século XX. Pode-se considerar como trabalhador informal aquele que pode influenciar na economia. A partir disso, vale ressaltar como informal aquele indivíduo que busca dentro do seu contexto uma forma de exercer uma profissão por conta própria, pois encontra barreiras que o inibem na demanda por uma oportunidade de emprego. Com intuito de diminuir as consequências ocasionadas pela atividade informal na economia, são imprescindíveis ações que sejam direcionadas ao combate da informalidade no país (SOUZA, 2010).

Para tanto, é importante enfatizar que esse conceito sobre os trabalhadores informais varia de acordo com as diretrizes do Estado, ou seja, ela é assimilada pela concepção em relação ao que é considerado formal. Pode-se dizer que no Brasil são considerados como informais os indivíduos que não apresentam registro na carteira de trabalho. A atividade informal está conectada às etapas da produtividade, trocas de bens e serviços, que são organizados pelo mercado e confrontam com as leis fiscais, comerciais e trabalhistas (JULIÃO, 2011).

A partir dessas considerações, é possível perceber a importância das políticas públicas no contexto da atividade informal. Observa-se que, no Brasil, encontra-se um número volumoso de empreendedores, que repetidamente encontram-se na informalidade e em condições inferiores, tendo em vista que não desfrutavam de situações que viessem favorecer a sua formalização, em razão da excessiva burocracia e exorbitante peso tributário que não era condizente com a sua situação. Com base nesse contexto, nasce a figura do microempreendedor individual em 2008, a partir disso os trabalhadores informais que disponham de algum tipo de comércio, têm a chance de dar início a sua empresa e finalmente sair da informalidade (AQUINO et al., 2012).

Conforme salienta o portal do microempreendedor, o microempreendedor individual é aquele indivíduo que exerce uma atividade por conta própria e que se formaliza como um pequeno empresário. Segundo o SEBRAE (2015), era necessária a inclusão de uma lei que viesse favorecer os pequenos empresários, em vista que fosse garantido um valor menor em relação aos tributos para que os indivíduos saíssem da informalidade. Foi então constituída a lei complementar de $\mathrm{n}^{\circ} 128$, em dezembro de 2008.

Evidencia-se que, com o intuito de criar uma forma mais adequada de disputa entre as empresas, foi gerada a lei geral das MEs (Lei complementar n 123/2006), bem como busca-se através da lei auxiliar no crescimento e concorrência entre as empresas, assim como usa-se dessa estratégia para melhorar a distribuição de renda, oferecer condições iguais aos cidadãos, contribuir para a geração de emprego, 
diminuição de atividades informais e estabilizar a economia. E com objetivo de diminuir de forma mais significativa o índice de trabalhadores informais, foi especificada a figura do microempreendedor individual por meio da Lei Complementar de 128/2008 (SEBRAE, 2013).

De acordo com Silva (2015), é possível destacar algumas vantagens em relação à formalização como microempreendedor individual, são elas: a presença de um empregado efetivado, bem como o registro no cadastro nacional de pessoas jurídicas (CNPJ), o que ajudará na abertura de uma conta em uma instituição bancária, assim como em realização de empréstimo e lançamento de nota fiscal. Também será concedido ao empreendedor individual o enquadramento no simples nacional, sendo assim, ficará fora da arrecadação dos tributos federarias (imposto de renda, PIS, COFINS, IPI e CSLL). Pagará apenas mensalmente um valor fixo que será atribuído a previdência e ao ICMS ou ao ISS. A partir dessas colaborações, o trabalhador formalizado fará proveito de auxílio doença, aposentadoria, auxílio maternidade.

Portanto, evidencia-se que as políticas públicas que impulsionam o empreendedorismo são de enorme importância para o desenvolvimento de uma nação. Ao criar o programa do microempreendedor individual, foi possível impulsionar a criação de novos negócios, assim como tirar da informalidade uma gama de brasileiros que exerciam sua atividade de maneira informal. Além da busca pela simplificação e da desburocratização, o objetivo dessa política é atuar com eficiência no desenvolvimento socioeconômico, bem como externar que existe a possibilidade de criar um negócio com vista nas oportunidades e, assim, fazer com que os empreendedores tenham o conhecimento sobre as vantagens e benefícios a partir da formalização como microempreendedor individual (ARAUJO, 2014).

Tabela 1: Vantagens de ser MEI segundo o portal do empreendedor

\begin{tabular}{|l|l|}
\hline Vantagens & Explicação \\
\hline I Isenção de impostos & $\begin{array}{l}\text { Tem isenção de tributos federais e paga um valor baixo em } \\
\text { tributos estaduais e municipais. }\end{array}$ \\
\hline 2 Emissão de nota fiscal & $\begin{array}{l}\text { O CNPJ possibilita a emissão de notas fiscais nas vendas e } \\
\text { prestação de serviços. }\end{array}$ \\
\hline 3 Direito previdenciário & $\begin{array}{l}\text { Ao se formalizar o empreendedor passa a ter direito a } \\
\text { aposentadoria por idade, auxilio doença e salário maternidade. }\end{array}$ \\
\hline 4 Facilidade na obtenção de empréstimo & $\begin{array}{l}\text { Com a formalização, os microempreendedores conseguem } \\
\text { facilmente obter um crédito no banco, na modalidade do } \\
\text { microempréstimo. }\end{array}$ \\
\hline 6 Aberviços gratuitos disponíveis & $\begin{array}{l}\text { Possui acesso gratuito de assessoria contábil, orientação do } \\
\text { Sebrae por meio de visitas. }\end{array}$ \\
\hline 7 Geração de CNPJ & $\begin{array}{l}\text { Poder movimentar as receitas do negócio em uma conta da } \\
\text { empresa. }\end{array}$ \\
\hline
\end{tabular}

Fonte: Adaptado de portaldoempreendedor.com

\section{Procedimentos metodológicos}

Pode-se definir metodologia científica como um agrupamento de funções que se relacionam em busca de um mesmo resultado, a fim de elaborar um estudo que possua uma veracidade, pois, por meio dele, o pesquisador conseguirá traçar um caminho em busca dos seus objetivos (LAKATOS, 2017). De acordo com Matias-Pereira (2016), metodologia pode ser definida como um grupo de processos, diretrizes e técnicas que são indispensáveis na construção de uma pesquisa científica. Por isso, possui um peso significante em vista que se relaciona a forma como essa pesquisa será desenvolvida.

A pesquisa utilizada neste trabalho é a de estudo descritivo, que se caracteriza pela busca de especificações e características de determinador grupo de pessoas, atividade, processos ou qualquer 
outro acontecimento que esteja sujeito a uma análise. Contudo, o estudo descritivo é útil para apresentar claramente as dimensões de um acontecimento ou situação, a partir de um determinado contexto. Pois, o seu objetivo é apenas medir e reunir informações, de modo que se chegue ao problema estudado, para que posteriormente, seja feita a análise e conclusão dos dados (HERNÁNDEZ, 2013).

Sendo assim, vale destacar que a abordagem do estudo se caracteriza em uma a pesquisa que será quantitativa. Portanto, a pesquisa quantitativa pode ser definida pela sua ligação com o pensamento lógico, focada na objetividade, pois os resultados serão expressos em percentuais (GERHARDT; SILVEIRA, 2009). Para o alcance do objetivo proposto, criaram-se quatro dimensões: condições favoráveis ao empreendedor, condições favoráveis ao empreendedor, estratégia de negócio e condições favoráveis ao negócio. Essas dimensões utilizadas na pesquisa foram construídas a partir dos principais benefícios do Microempreendedor Individual descritos no portal do empreendedor (www.portaldoempreendedor.gov.br), como podemos ver na tabela 1.

Portanto, o objetivo geral da pesquisa é analisar a percepção dos empreendedores acerca dos benefícios do programa governamental do microempreendedor individual. Para tanto, para a coleta de dados utilizou-se de aplicação de formulário com uma amostra de 136 empreendedores, que foi aplicado in loco na Feira do João Paulo na Cidade de São Luís do Maranhão. O formulário aplicado na pesquisa (apêndice A) utilizou afirmações com opções baseadas na escala Likert, as quais foram: concordo totalmente, concordo, indiferente, discordo e discordo totalmente. Após a coleta para a tabulação dos dados, utilizou-se o auxílio do Programa Excel para gerar os resultados e assim analisálos.

Tabela 2: Dimensões utilizadas na pesquisa

\begin{tabular}{|c|c|c|}
\hline DIMENSÕES & BENEFÍCIOS & AFIRMAÇÕES \\
\hline \multirow{4}{*}{$\begin{array}{l}\text { CONHECIMENTO } \\
\text { ACERCA DO PROGRAMA }\end{array}$} & \multirow[t]{4}{*}{ Conhecer o MEI. } & $\begin{array}{l}\text { Tenho conhecimento acerca do programa } \\
\text { Microempreendedor Individua- MEI }\end{array}$ \\
\hline & & $\begin{array}{l}\text { Tenho conhecimento das vantagens que o } \\
\text { programa do MEI me apresenta. }\end{array}$ \\
\hline & & Conheço o portal do empreendedor. \\
\hline & & $\begin{array}{l}\text { Sei o que é necessário para me formalizar } \\
\text { com MEI. }\end{array}$ \\
\hline \multirow{3}{*}{$\begin{array}{l}\text { CONDIÇÕES } \\
\text { FAVORÁVEIS } \\
\text { EMPREENDEDOR }\end{array}$} & \multirow[t]{3}{*}{ Direito previdenciário. } & $\begin{array}{l}\text { Não poder ter salário maternidade é uma } \\
\text { desvantagem de não estar registrado. }\end{array}$ \\
\hline & & $\begin{array}{l}\text { Não poder me aposentar por idade como } \\
\text { empreendedor é uma desvantagem de não } \\
\text { estar devidamente registrado. }\end{array}$ \\
\hline & & $\begin{array}{l}\text { Não poder ter Auxilio doença é uma } \\
\text { desvantagem de não estar registrado. }\end{array}$ \\
\hline \multirow{4}{*}{$\begin{array}{l}\text { ESTRATÉGIA } \\
\text { NEGÓCIO. }\end{array}$} & Emissão de nota fiscal. & $\begin{array}{l}\text { As minhas vendas aumentariam se } \\
\text { pudesse emitir nota fiscal. }\end{array}$ \\
\hline & Facilidade na obtenção de empréstimo. & $\begin{array}{l}\text { Fazer empréstimos bancários ajudaria no } \\
\text { crescimento do me negócio. }\end{array}$ \\
\hline & Abertura de conta empresarial. & $\begin{array}{l}\text { Ter uma conta empresarial melhoraria o } \\
\text { funcionamento do meu negócio }\end{array}$ \\
\hline & Geração do CNPJ & $\begin{array}{l}\text { Ter um CNPJ garante maior confiança ao } \\
\text { meu negócio. }\end{array}$ \\
\hline $\begin{array}{l}\text { CONDIČÕES } \\
\text { FAVORÁVEIS } \\
\text { NEGÓCIO }\end{array}$ & Serviços gratuitos disponíveis. & $\begin{array}{l}\text { Ter orientação do SEBRAE por meio de } \\
\text { visitas ajudaria no crescimento do meu } \\
\text { negócio. }\end{array}$ \\
\hline
\end{tabular}




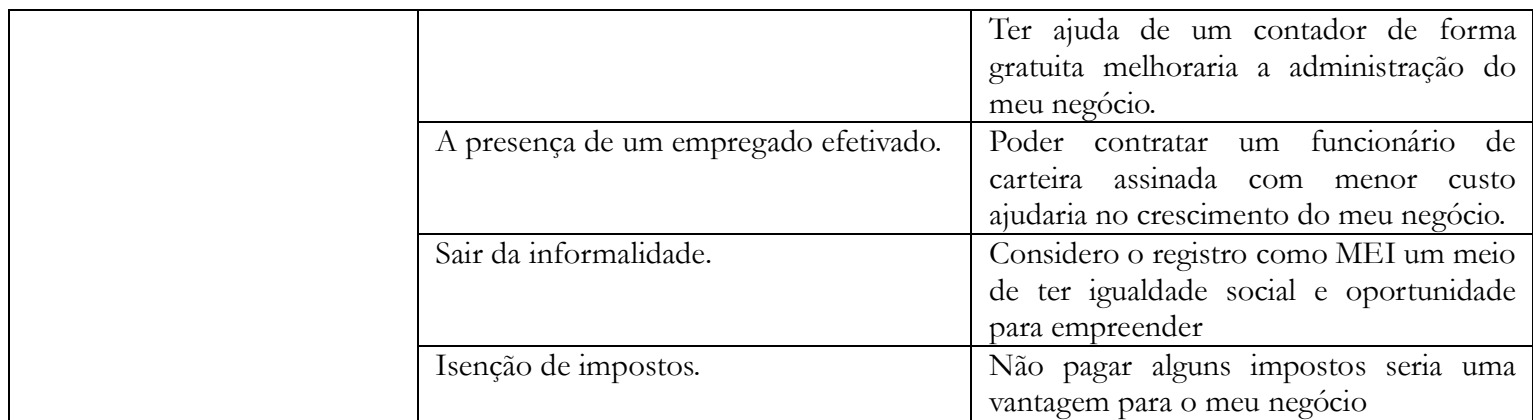

Fonte: Dados da Pesquisa, 2018.

\section{Apresentação e análise dos resultados}

A pesquisa foi realizada com uma amostra de 136 empreendedores da cidade de São Luís, que exercem suas atividades em um centro comercial, situado na feira do bairro do João Paulo. Consequentemente, foram aplicados 136 formulários pessoalmente com cada entrevistado. Como forma de alcançar o objetivo proposto nessa pesquisa, apontado para analisar qual a percepção dos empreendedores em relação aos benefícios do programa Microempreendedor Individual, foi necessária a verificação de alguns dados socioeconômicos, bem como de algumas afirmações presentes no formulário aplicado.

\section{Análise Socioeconômica}

Conforme o resultado da pesquisa, constatou-se que existe uma representatividade significativa do público feminino na atividade empreendedora. Com um percentual de $57 \%$ do total, um pouco maior do que o público masculino que representa um percentual de $43 \%$. Ao analisar a faixa etária dos entrevistados, observa-se que $49 \%$ do total possui idade entre 36 a 49 anos, bem como $19 \%$ do percentual estão inclusos na faixa etária de 50 a 66 anos. A partir dessa amostra, pode-se compreender que os empreendedores em sua maioria representam um público de pessoas mais velhas, se comparado a faixa etária de 18 a 25 anos que representa um percentual de $11 \%$.

Quanto aos dados relacionados ao nível de escolaridade dos empreendedores, foi possível perceber que, em sua maioria, com um percentual de $51 \%$, possui o ensino médio completo. Ao somar o percentual de quem possui ensino superior completo e incompleto, totaliza um percentual de $21 \%$. Ao avaliar a variável sobre o empreendimento, nota-se que $67 \%$ dos negócios são a única fonte de renda do empreendedor e apenas 33\% têm o negócio apenas como uma renda completar. Pode-se empiricamente deduzir que esse percentual representa aquelas pessoas que vislumbraram uma oportunidade para empreender. Vale, Corrêa e Reis (2014) explicam que o empreendedor por oportunidade corresponde àquela parcela da população que demanda a ocupação empreendedora ao conjecturar uma oportunidade de desenvolver um negócio, dentre outras opções em que poderia seguir.

Um outro aspecto importante é que algumas evidências podem ser apontadas, dentre elas, nota-se o pequeno percentual dos entrevistados registrados no MEI, a saber $29 \%$. Em contrapartida, os números evidenciam que $71 \%$ ainda estão na informalidade. Souza (2010) explica que com intuito de diminuir as consequências ocasionadas pela atividade informal na economia, são imprescindíveis ações que sejam direcionadas ao combate da informalidade no país.

\section{Análise dos Dados Obtidos}

A tabela 3 apresenta o resultado tabulado das afirmativas do formulário aplicado aos 136 entrevistados, bem como o resultado em percentual referente a cada dimensão. As afirmações foram construídas com base no portal do empreendedor, que apresenta uma série de benefícios para os empreendedores 
que desejam sair da informalidade e registrar-se como microempreendedor individual. Por meio de uma análise feita a partir da escala likert, sendo na tabela 3, o 1 (discordo totalmente), o 2 (discordo), o 3 (indiferente), o 4 (concordo) e o 5 (concordo totalmente), chegou-se a alguns resultados que visam chegar ao objetivo geral da pesquisa, que é analisar a percepção dos empreendedores em relação às vantagens de se tornar um MEI.

Tabela 3: Resultado dos dados tabulados por Dimensão

\begin{tabular}{|c|c|c|c|c|c|c|c|}
\hline DIMENSÃO & BENEFÍCIOS & AFIRMATIVA & 1 & 2 & 3 & 4 & 5 \\
\hline \multirow{4}{*}{$\begin{array}{l}\text { CONHECIM } \\
\text { ENTO } \\
\text { ACERCA DO } \\
\text { PROGRAMA }\end{array}$} & \multirow{4}{*}{$\begin{array}{l}\text { Conhecimento do } \\
\text { MEI }\end{array}$} & $\begin{array}{lrr}1 & \text { Tenho } & \text { conhecimento acerca do } \\
\text { programa } & \text { Microempreendedor } \\
\text { Individua- } & \text { MEI } & \end{array}$ & $32 \%$ & $10 \%$ & $2 \%$ & $43 \%$ & $13 \%$ \\
\hline & & $\begin{array}{l}2 \text { Tenho conhecimento das vantagens } \\
\text { que o programa do MEI me apresenta. }\end{array}$ & $52 \%$ & $26 \%$ & $4 \%$ & $10 \%$ & $7 \%$ \\
\hline & & 3 Conheço o portal do empreendedor. & $56 \%$ & $22 \%$ & $2 \%$ & $15 \%$ & $4 \%$ \\
\hline & & $\begin{array}{l}4 \text { Sei o que é necessário para me } \\
\text { formalizar com MEI. }\end{array}$ & $40 \%$ & $13 \%$ & $2 \%$ & $34 \%$ & $11 \%$ \\
\hline \multicolumn{3}{|l|}{ TOTAL } & $45 \%$ & $18 \%$ & $3 \%$ & $26 \%$ & $9 \%$ \\
\hline \multirow{6}{*}{$\begin{array}{l}\text { CONDIÇÕE } \\
\text { S } \\
\text { FAVORÁVEI } \\
\text { S AO AO } \\
\text { NEGÓCIO }\end{array}$} & $\begin{array}{ll}\begin{array}{l}\text { Isenção } \\
\text { impostos }\end{array} & \text { de }\end{array}$ & $\begin{array}{l}5 \text { Não pagar alguns impostos seria uma } \\
\text { vantagem para o meu negócio }\end{array}$ & $4 \%$ & $9 \%$ & $18 \%$ & $51 \%$ & $18 \%$ \\
\hline & \multirow{2}{*}{$\begin{array}{l}\text { Serviços gratuitos } \\
\text { disponíveis }\end{array}$} & $\begin{array}{l}13 \text { Ter ajuda de um contador de forma } \\
\text { gratuita melhoraria a administração do } \\
\text { meu negócio. }\end{array}$ & $20 \%$ & $5 \%$ & $4 \%$ & $43 \%$ & $28 \%$ \\
\hline & & $\begin{array}{l}14 \text { Ter orientação do Sebrae por meio de } \\
\text { visitas ajudaria no crescimento do meu } \\
\text { negócio. }\end{array}$ & $11 \%$ & $4 \%$ & $4 \%$ & $50 \%$ & $31 \%$ \\
\hline & \multicolumn{2}{|l|}{ TOTAL } & $15 \%$ & $5 \%$ & $4 \%$ & $47 \%$ & $29 \%$ \\
\hline & $\begin{array}{ll}\text { Sair } & \mathrm{da} \\
\text { informalidade }\end{array}$ & $\begin{array}{l}15 \text { Considero o registro como MEI um } \\
\text { meio de ter igualdade social e } \\
\text { oportunidade para empreender. }\end{array}$ & $5 \%$ & $6 \%$ & $14 \%$ & $55 \%$ & $20 \%$ \\
\hline & $\begin{array}{l}\text { A presença de um } \\
\text { empregado } \\
\text { efetivado }\end{array}$ & $\begin{array}{l}16 \text { Poder contratar um funcionário de } \\
\text { carteira assinada com um menor custo } \\
\text { ajudaria no crescimento do meu negócio. }\end{array}$ & $24 \%$ & $12 \%$ & $8 \%$ & $40 \%$ & $16 \%$ \\
\hline \multicolumn{3}{|c|}{ TOTAL } & $16 \%$ & $8 \%$ & $10 \%$ & $57 \%$ & $29 \%$ \\
\hline \multirow{3}{*}{$\begin{array}{l}\text { CONDIÇÕE } \\
\text { S } \\
\text { FAVORÁVEI } \\
\text { S AO } \\
\text { EMPREEND } \\
\text { EDOR }\end{array}$} & \multirow{3}{*}{$\begin{array}{l}\text { Direito } \\
\text { previdenciário }\end{array}$} & $\begin{array}{l}7 \text { Não poder me aposentar por idade } \\
\text { como empreendedor é uma desvantagem } \\
\text { de não estar registrado. }\end{array}$ & $14 \%$ & $7 \%$ & $5 \%$ & $63 \%$ & $11 \%$ \\
\hline & & $\begin{array}{l}8 \text { Não poder ter auxilio doença é uma } \\
\text { desvantagem de não estar registrado. }\end{array}$ & $13 \%$ & $3 \%$ & $3 \%$ & $65 \%$ & $17 \%$ \\
\hline & & $\begin{array}{l}9 \text { Não poder ter salário maternidade é } \\
\text { uma desvantagem de não estar registrado. }\end{array}$ & $40 \%$ & $16 \%$ & $3 \%$ & $31 \%$ & $10 \%$ \\
\hline \multicolumn{3}{|c|}{ TOTAL } & $22 \%$ & $9 \%$ & $4 \%$ & $53 \%$ & $13 \%$ \\
\hline \multirow{3}{*}{$\begin{array}{l}\text { ESTRATÉGI } \\
\text { A DÉCIOS } \\
\text { NEGÓCIOS }\end{array}$} & $\begin{array}{l}\text { Emissão de nota } \\
\text { fiscal }\end{array}$ & $\begin{array}{l}6 \text { As minhas vendas aumentariam se eu } \\
\text { pudesse emitir nota fiscal }\end{array}$ & $43 \%$ & $21 \%$ & $12 \%$ & $20 \%$ & $4 \%$ \\
\hline & $\begin{array}{l}\text { Abertura de conta } \\
\text { empresarial }\end{array}$ & $\begin{array}{l}10 \text { Ter uma conta empresarial melhoraria } \\
\text { o funcionamento do meu negócio. }\end{array}$ & $11 \%$ & $4 \%$ & $10 \%$ & $59 \%$ & $17 \%$ \\
\hline & $\begin{array}{|ll|}\text { Facilidade } & \text { na } \\
\text { obtenção } & \text { de } \\
\text { empréstimo } & \\
\end{array}$ & $\begin{array}{l}11 \text { Fazer empréstimos bancários ajudaria } \\
\text { no crescimento do meu negócio. }\end{array}$ & $32 \%$ & $10 \%$ & $11 \%$ & $31 \%$ & $17 \%$ \\
\hline
\end{tabular}


Microempreendedor Individual e as Vantagens da Formalização

\begin{tabular}{|l|l|l|l|l|l|l|l|l|} 
& Geração do CNPJ & $\begin{array}{l}12 \text { Ter um CNPJ garante maior confiança } \\
\text { no meu negócio. }\end{array}$ & $4 \%$ & $2 \%$ & $7 \%$ & $53 \%$ & $32 \%$ \\
\hline TOTAL & $23 \%$ & $9 \%$ & $10 \%$ & $41 \%$ & $18 \%$ \\
\hline
\end{tabular}

Fonte: Dados da Pesquisa, 2018.

Nesse contexto, a partir da tabela 3, criou-se o gráfico 1 para analisar-se o nível de concordância e discordância dos pesquisados com as dimensões da pesquisa, a fim de analisar-se a percepção dos empreendedores quanto aos benefícios do Programa Microempreendedor Individual descritos no portal do empreendedor. O gráfico 1 apresenta a média em percentual de cada opção da escala likert por dimensão.

Gráfico 1: Resultados por Dimensão

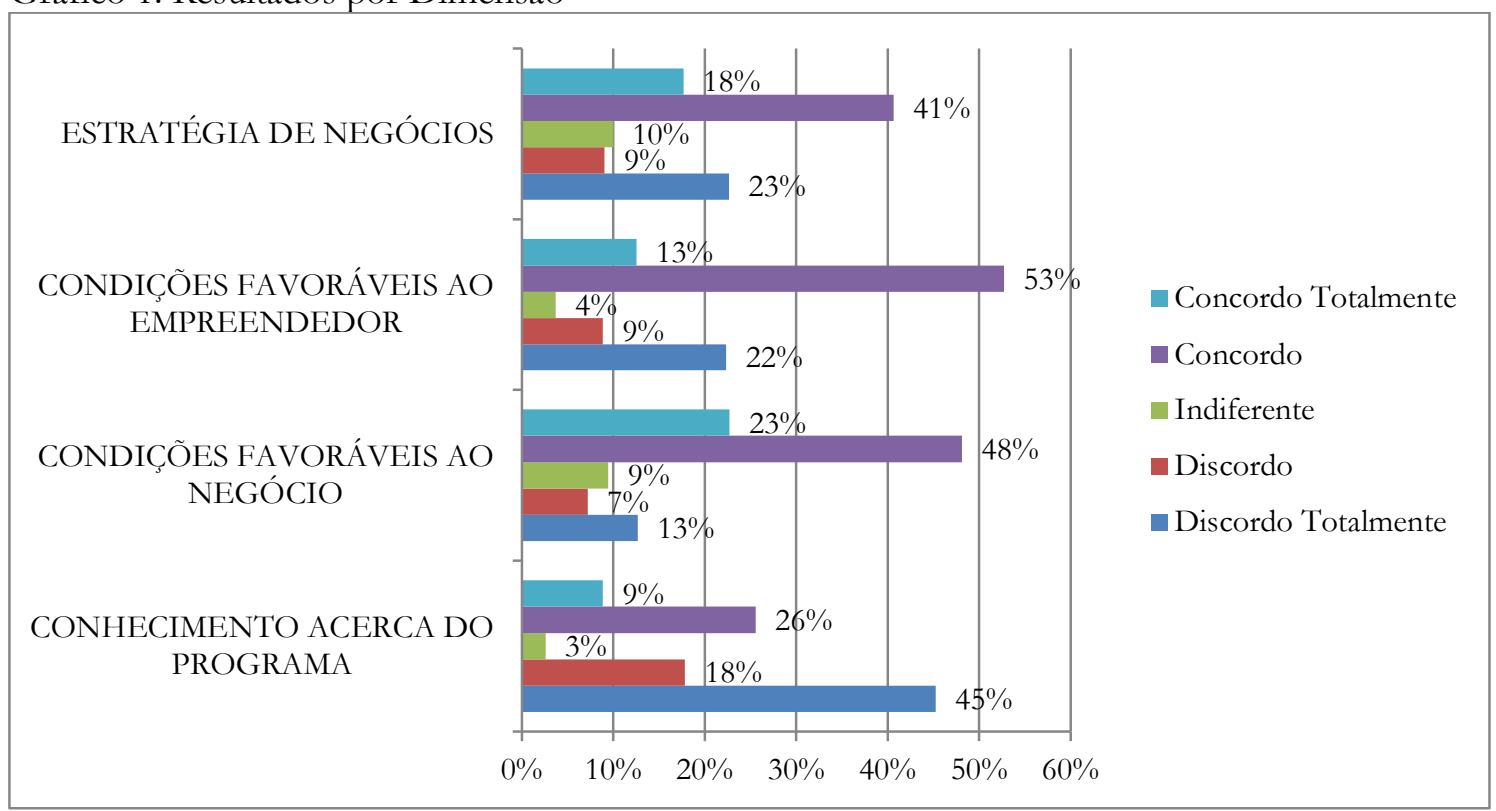

Fonte: Dados da Pesquisa, 2018.

$\mathrm{Na}$ primeira dimensão, a qual trata do conhecimento acerca do programa MEI, percebe-se a discrepância existente entre o número de empreendedores entrevistados que concordam com as assertivas e aqueles que discordam. Nota-se que a maior parte dos empreendedores entrevistados, com um percentual de $63 \%$, não apresentam o devido conhecimento em relação ao programa e aos benefícios a quem faz o devido registro no MEI. Apenas um percentual de $35 \%$ possui conhecimento do que é o MEI e das suas vantagens.

Para Araújo (2014), o objetivo da política do microempreendedor individual é atuar com eficiência no desenvolvimento socioeconômico, bem como externar que existe a possibilidade de criar um negócio com vista nas oportunidades. E assim, fazer com que os empreendedores tenham o conhecimento sobre as vantagens e benefícios a partir da formalização como microempreendedor individual. A partir desse entendimento, percebe-se a existência de uma lacuna e, por isso, considera-se necessária a informação em relação ao programa e suas vantagens, de maneira mais clara e divulgada aos empreendedores.

Baseado em alguns benefícios do portal do empreendedor, a saber, isenção de impostos, serviços gratuitos, sair da informalidade e ter-se um empregado efetivado, analisou-se a segunda dimensão de condições favoráveis ao negócio. Conforme o gráfico 1, 23\% concordam totalmente e 48\% concordam que os benéficos de ser MEI descritos no portal do empreendedor promovem condições 
favoráveis ao negócio. Entretanto, quando se volta para a dimensão de conhecimento acerca do MEI, verifica-se que os empreendedores entrevistados desconhecem os benefícios do MEI, ainda que consideram que estes promovem condições favoráveis para os seus negócios.

Ao avaliar a dimensão de condições favoráveis ao empreendedor, contendo afirmativas relacionadas aos benefícios previdenciários, constatou-se resultados relevantes. Com um percentual de $66 \%$ de concordância, os empreendedores consideram que uma desvantagem de não ser registrado no programa MEI é não poder receber esses auxílios. No entanto, $35 \%$ dos respondentes do formulário discordam ou são indiferentes a esses benefícios. Infere-se que estes resultados estão dispostos desta maneira, por conta da faixa etária dos analisados que compreende cerca de $49 \%$ do total, a idade entre 36 a 49 anos, e 19\% do total, a idade de 50 a 66 anos.

Para o Sebrae (2013, p.10), com o intuito de criar uma forma mais adequada de disputa entre as empresas, foi gerada a lei geral das MEIs (Lei complementar $n^{\circ} 123 / 2006$ ), bem como busca-se através da lei auxiliar no crescimento e concorrência entre as empresas, assim como usa-se dessa estratégia para melhorar a distribuição de renda e oferecer condições iguais aos cidadãos.

Nessa perspectiva, ao analisar a dimensão estratégia de negócios, observa-se que com um total de $42 \%$ de discordância e indiferença, uma parte considerável dos empreendedores pesquisados não consideram os benefícios de emissão de nota fiscal e de facilidade na obtenção de empréstimos relacionados a essa estratégia como algo positivo para o seu negócio. 
Gráfico 2: Benefícios do MEI conforme portal do empreendedor

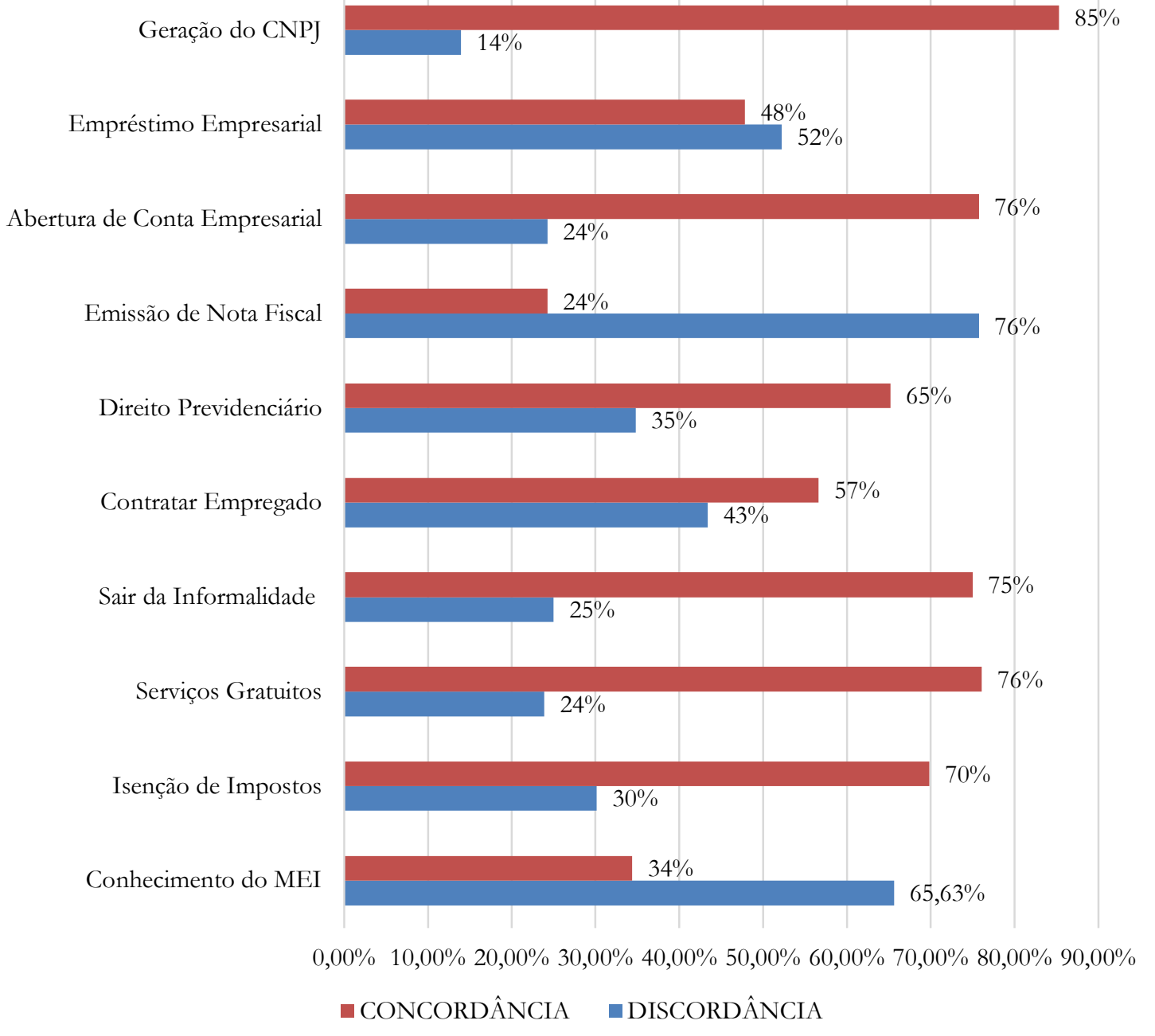

Fonte: Dados da Pesquisa, 2018.

Mediante os resultados dispostos na tabela 3, criou-se o gráfico 2 para descrever o nível de concordância e discordância dos pesquisados em relação aos benefícios do MEI descritos no portal do empreendedor. Sendo que, para avaliar a concordância, levou-se em consideração o somatório da opção "concordo totalmente" com a opção "concordo" e, para discordância, somou-se as opções "discordo totalmente", "discordo" e "indiferente".

Nota-se que na percepção dos pesquisados, dentre os benefícios apresentados aos empreendedores, alguns possuem um maior destaque. Com um percentual de $85 \%$ de concordância, o benefício mais importante na visão dos empreendedores é possuir um CNPJ, pois agrega maior credibilidade ao negócio. Em segundo lugar, constam empatados os benefícios de possuir uma conta empresarial e serviços gratuitos, como algo positivo, tendo em vista que $76 \%$ dos empreendedores avaliam a assertiva como verdadeira.

No entanto, observa-se que dentre os benefícios proporcionados aos empreendedores que são registrados ou desejam se formalizar, alguns apresentam pouca relevância para os pesquisados. Constata-se, analisando os números, que há nas respostas uma grande variação no que tange o benefício de facilidade na obtenção de empréstimo. Já que de "discordo totalmente" a "concordo totalmente" os resultados são bem parecidos. 
Sendo assim, com um percentual de $76 \%$ de discordância, a assertiva relacionada à emissão de nota fiscal foi a que foi observada como a de menor importância para os empreendedores. Infere-se diante destes resultados que a maioria dos empreendedores analisados não necessita emitir nota fiscal para poder desempenhar as suas atividades empresariais.

\section{Considerações finais}

Diante do crescente número de empreendedores informais em meados do século XX, percebeu-se a necessidade da criação de um programa que viesse ofertar a estes trabalhadores benefícios que tornasse vantajoso migrar da informalidade para a formalidade. Trazendo, assim, não somente benefícios para o empreendedor e seu negócio, mas também para a sociedade por meio do desenvolvimento socioeconômico que estes empreendimentos trazem. Sendo assim, foi então constituída a figura do microempreendedor individual, programa que possui como finalidade tirar da informalidade milhões de empreendedores.

A pesquisa teve como problemática o seguinte questionamento: como os empreendedores percebem os benefícios do programa governamental do Microempreendedor Individual? Este problema foi respondido, haja vista que a partir das dimensões criadas por meio dos benefícios descritos no portal do empreendedor, observou-se com base nos resultados que a maior parte dos empreendedores não conhece o programa e os benefícios atrelados a ele. No entanto, ao analisarem as assertivas que faziam referência a esses benefícios, percebeu-se que os pesquisados apresentam uma visão positiva em relação a essas vantagens.

Diante do que foi exposto, este artigo teve como objetivo analisar a percepção dos empreendedores acerca dos benefícios do programa governamental do Microempreendedor Individual. Os resultados obtidos mostram que, apesar de muitos empreendedores não serem formalizados e não conhecerem esses benefícios, apresentam uma percepção positiva e consideram alguns benefícios a saber: possuir um CNPJ, ter uma conta empresarial e os serviços gratuitos, como os mais relevantes para um melhor funcionamento do negócio.

Cabe ressaltar que este artigo não exaure a temática abordada, mas enseja novos estudos acerca do programa MEI. Em relação à análise de resultados, por ser uma temática pouco explorada, obteve-se dificuldade para fazer a relação entre os resultados obtidos e a teoria utilizada na pesquisa.

\section{Referências}

AQUINO, Albani Barroso et al. Políticas públicas para os empreendedores individuais: um estudo de caso no município de Senhor do Bonfim-Ba. RAC - Revista de Administração e Contabilidade. Faculdade Anísio Teixeira (FAT), Feira de Santana-Ba, v. 4, n. 1, p. 54-66, janeiro/abril, 2012. Disponível

em:<https://www.researchgate.net/publication/275344821_Politicas_publicas_para_os_empreende dores_individuais_um_estudo_de_caso_no_municipio_de_Senhor_do_Bonfim-

Ba_Public_policies_for_individual_entrepreneurs_a_case_study_in_the_municipality_of_Senhor_d o_B >. Acesso em: 12/12/2019.

ARAUJO, Marieta Medeiros de. A visão dos artesãos sobre o programa microempreendedor individual - MEI: Uma investigação na Vila dos Artesãos de Campina Grande - PB. 20 pp. Trabalho de conclusão de curso (Graduação em Ciências Contábeis). Universidade Estadual da Paraíba, 


Campina Grande $\quad-\quad 2014.20$ PB. Disponível

em: $<$ http://dspace.bc.uepb.edu.br/jspui/bitstream/123456789/5342/1/PDF\%20-

$\% 20$ Marietta $\% 20$ Medeiros $\% 20$ de $\% 20$ Ara $\%$ C3\%BAjo.pdf $>$. Acesso em: 12/12/2019.

BAGGIO, Adelar Francisco; BAGGIO, Daniel Knebel. Empreendedorismo: Conceitos e definições. Revista de empreendedorismo, inovação e tecnologia, v. 1, n. 1, p. 25-38, 2015. Disponível em: $<$ https://seer.imed.edu.br/index.php/revistasi/article/viewFile/612/522>. Acessado em: 30/04/2018.

BARROS, Aluízio Antônio de. PEREIRA, Cláudia Maria Miranda de Araújo. Empreendedorismo e Crescimento Econômico: uma Análise Empírica. RAC, Curitiba, v. 12, n. 4, p. 975-993, Out./Dez. 2008. Disponível em: <http://www.scielo.br/pdf/rac/v12n4/05.pdf>. Acessado em: 30/04/2018.

BERNARDO, Nathalia; VIEIRA, Edson Trajano; ARAUJO, Elvira Aparecida Simões. A relevância da atividade empreendedora para o desenvolvimento econômico de um país. Revista Científica online-Tecnologia, Gestão e Humanismo, v. 2, n. 1, 2013. Disponível em: $<$ http://www.fatecguaratingueta.edu.br/revista/index.php/RCO-TGH/article/view/22>.

Acessado em: 30/04/2018.

COSTA, A. M. da; BARROS, D. F.; CARVALHO, J. L. F. A Dimensão Histórica dos Discursos acerca do Empreendedor e do Empreendedorismo. RAC, Curitiba, v. 15, n. 2, art. 1, pp. 179-197, Mar./Abr. 2011. Disponível em: $\quad<$ http://www.scielo.br/scielo.php?script=sci_arttext\&pid=S1415$65552011000200002>$. Acessado em: 30/04/2018.

GLOBAL ENTREPRENEURSHIP MONITOR - GEM 2015. Empreendedorismo no Brasil: 2015 \uritiba: IBQP, 2015. Disponível em: $<$ http://www.bibliotecas.sebrae.com.br/chronus/ARQUIVOS_CHRONUS/bds/bds.nsf/c6de907f e0574c8ccb36328e24b2412e/\$File/5904.pdf\&gt;.> Acesso em: 05/05/2018

\section{GLOBAL ENTREPRENEURSHIP MONITOR - GEM 2016. Empreendedorismo no Brasil: 2016 Curitiba: IBQP, $2016 . \quad$ Disponível em: <http://www.bibliotecas.sebrae.com.br/chronus/ARQUIVOS_CHRONUS/bds/bds.nsf/941a51d d04d5e55430088db11a262802/\$File/7592.pdf>. Acessado em: 05/05/2018.}

GERHARDT, Tatiana Engel. SILVEIRA,Denise Tolfo. Métodos de pesquisa. [organizado por]coordenado pela Universidade Aberta do Brasil - UAB/UFRGS e pelo Curso de Graduação Tecnológica - Planejamento e Gestão para o Desenvolvimento Rural da SEAD/UFRGS. - Porto Alegre: Editora da UFRGS, 2009. Disponível em: $<$ http://www.ufrgs.br/cursopgdr/downloadsSerie/derad005.pdf. $>$ Acessado em: 30/04/2018.

HAVRELUCK, Bruna Fernanda; LEAL, Larissa Estela; BERTOLAZO, Ivana Nobre. Oportunidade ou Necessidade? Um estudo sobre as mulheres empreendedoras no segmento de estética na cidade de Apucarana/ PR. Anais V SINGEP- São Paulo- SP- BRASIL- 20,21 e 22/11/2016. Disponível em: < https://singep.org.br/5singep/resultado/634.pdf>. Acessado em: 30/04/2018.

HERNADEZ, Roberto; COLLADO, Carlos Fernández; LUCIO, Maria del Pilar Baptista. Metodologia de Pesquisa. -5. ed.- Porto Alegre: Penso,2013

JULIÃO, F. Fatores Determinantes da Satisfação de usuários do programa microempreendedor individual. Teoria e Prática em Administração, v.4, n.1, 2014, pp.156-179. Disponível em: $<$ https://periodicos.ufpb.br/index.php/tpa/article/view/18322/10662>. Acessado em: 30/04/2018. 
LAKATOS, Eva Maria. Fundamentos de metodologia cientifica. - 8.ed. -São Paulo: Atlas, 2017.

LASCALA, Artur Junqueira; SAETA, Juan Manuel Pereira; ANDRADE, Sergio Rodrigo. Empreendedorismo e desenvolvimento local: o Programa Goiás Mais Empreendedor. 2016. 90 f. Dissertação (Mestrado)- Escola de Administração de Empresas de São Paulo. 2016. Disponível em: $<$ https://bibliotecadigital.fgv.br/dspace/bitstream/handle/10438/17446/DISSERTA\%c3\%87\%c3 $\% 83$ O_FINAL.pdf?sequence $=4$ \&isAllowed $=\mathrm{y}>$. Acessado em: 15/05/2018.

MATIAS-PEREIRA, José. Manual de metodologia de pesquisa cientifica / -4. ed.- São Paulo: Atlas, 2016.

MOREIRA, José de Octávio de Campos. Economia: notas introdutórias. -2. ed. - São Paulo: Atlas,2009.

OLIVEIRA, Gilson Batista de. Uma discussão sobre o conceito de desenvolvimento. Rev. FAE, Curitiba, v.5, n.2, p.37-48, maio/ago. 2002. Disponível em: <https://revistafae.fae.edu/revistafae/article/view/477.> Acessado em: 15/05/2018.

ROCHA, Estevão Lima de Carvalho. Oportunidade ou necessidade? Um estudo do impacto do empreendedorismo no desenvolvimento econômico. Revista Gestão em Análise, Fortaleza, v. 3, n. 1/2, p. 31-46, abr. 2014. ISSN 2359-618X. Disponível em: $<$ http://periodicos.unichristus.edu.br/index.php/gestao/article/view/146>. Acessado em: $30 / 04 / 2018$

SEBRAE, Serviço Brasileiro de Apoio às Micro e Pequenas Empresas 5 anos: microempreendedor individual - MEI: um fenômeno de inclusão produtiva. / SEBRAE. - Brasília: Sebrae, 2015. Disponível em: <https://bibliotecas.sebrae.com.br/chronus/ARQUIVOS_CHRONUS/bds/bds.nsf/f50b81419a2 6467c89174b15d48bd8af/\$File/5359.pdf>. Acessado em: 30/04/2018

SEBRAE. Perfil do Empreendedor individual. Disponível em: <http://ambientedigital.sebraers.com.br/Download/Arquivos/Perfil_MEI_2013.pdf.>. Acesso em: 10/06/2018.

SILVA, Elisandra Ribeiro da. Microempreendedor Individual: Dificuldades encontradas pelos microempreendedores individuais na cidade de Taquara-RS. 42 p. Monografia do Curso de Ciências Contábeis - Departamento de Ciências Contábeis, Universidade Federal de Santa Catarina, Florianópolis. 2015.

Disponível em:<https://repositorio.ufsc.br/bitstream/handle/123456789/163188/Elisandra\%20Ribeiro\%20da $\% 20$ Silva.pdf? sequence $=1$ \&isAllowed $=\mathrm{y}>$. Acesso em: 10/06/2018.

SOUZA, Dayanne Marlene. Os principais benefícios proporcionados ao trabalhador informal para formalização através do Microempreendedor Individual. 95 fls. Monografia (Curso de Ciências Contábeis) - Universidade Federal de Santa Catarina, Florianópolis, 2010. Disponível em:<https://repositorio.ufsc.br/bitstream/handle/123456789/127035/Contabeis294059.pdf?seque nce $=1 \&$ is Allowed $=y>.12 / 02 / 2018$.

VALE, Gláucia Maria Vasconcelos; CORREAA, Victor Silva; FRANCISCO DOS REIS, Renato. Motivações para o empreendedorismo: necessidade versus oportunidade? RAC-Revista de Administração Contemporânea, v. 18, n. 3, 2014. Disponível em: $<$ http:/ /www.scielo.br/scielo.php?script=sci_arttext\&pid=S141565552014000300005\&lng=pt\&tlng $=$ pt $>$. Acessado em: 12/02/2018. 